\title{
Militarisation de l'espace et représentations sociales du conflit à Chypre du Nord
}

Militarization of space and social representations of the conflict in Northern Cyprus

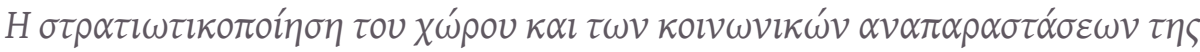

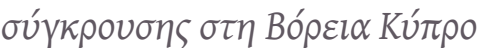

\section{Mathieu Petithomme}

\section{OpenEdition}

\section{Journals}

Édition électronique

URL : https://journals.openedition.org/ceb/15349

DOI : 10.4000/ceb.15349

ISSN : 2261-4184

Éditeur

INALCO

\section{Édition imprimée}

ISBN : 9782858313341

ISSN : 0290-7402

\section{Référence électronique}

Mathieu Petithomme, « Militarisation de l'espace et représentations sociales du conflit à Chypre du Nord », Cahiers balkaniques [En ligne], 46 | 2020, mis en ligne le 25 février 2020, consulté le 06 juillet 2021. URL : http://journals.openedition.org/ceb/15349 ; DOI : https://doi.org/10.4000/ceb.15349

\section{(c) (1) \&}

Cahiers balkaniques est mis à disposition selon les termes de la Licence Creative Commons Attribution - Pas d'Utilisation Commerciale 4.0 International. 


\title{
Militarisation de l'espace et représentations sociales du conflit à Chypre du Nord
}

\author{
Militarization of space and social representations \\ of the conflict in Northern Cyprus
}

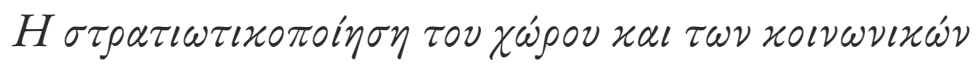

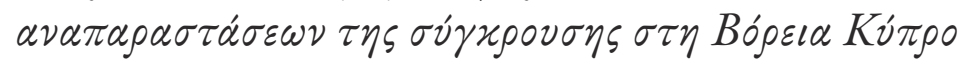

\author{
Mathieu Petithomme \\ Université de Franche-Comté
}

Comment procède et quel est l'impact psychosocial de la militarisation de l'espace à Chypre du Nord ? Territoire de $3355 \mathrm{~km}^{2}$ (36\% de la superficie de l'île), contrôlé par l'armée turque depuis la partition du 20 août 1974 et autoproclamé indépendant depuis 1983, la « République turque de Chypre du Nord 》 (RTCN, Kuzey Kibrıs Türk Cumburiyet, KKTC en turc) n'a «pas d'existence légale » suivant la résolution 541 du Conseil de sécurité de l'ONU du 18 novembre 1983. Dotée d'un gouvernement, d'une «administration civile» (devlet memurluğu), d'un Président et d'un Parlement élus de façon régulière depuis la création de l'«État turc fédéré de Chypre » en 1975, la RTCN a longtemps été dominée par Rauf Denktaş (1975-2005) et son parti de l'unité nationale (Ulusal Birlik Partisi, UBP), fidèle au nationalisme turc, dont le slogan demeure «la partition ou la mort » (Ya Taksim Ya Ölüm). De 2005 à 2009, et à la suite des élections législatives du 28 juillet 2013, l'opposition de centre gauche menée par Özkan Yorgancioğlü du parti républicain turc (Cumburiyetci Türk Partisi, CTP), gouverna en coalition avec le parti démocrate (Demokrat Parti, DP), nationaliste, mais moins intransigeant que l'UBP, dont le dirigeant Derviş Eroğlu a dominé la présidence de 2010 à 2015, avant d'être battu par le candidat de gauche, Mustafa Akınc1, lors de la présidentielle d'avril 2015. Reconnue uniquement par la Turquie, la « RTCN » constitue un «État de facto», à savoir «un leadership politique organisé qui a 
acquis une capacité suffisante pour fournir des services gouvernementaux à une population au sein d'une aire territoriale donnée, sur laquelle un contrôle effectif est maintenu durant une période de temps significative », mais qui est dépourvu de reconnaissance internationale ${ }^{1}$.

30000 militaires turcs stationnent toutefois en RTCN depuis 1974. Les slogans patriotiques sur les murs, les casernes, barbelés et guérites, créent un espace physique militarisé, qui affecte les représentations que se font les Chypriotes turcs de leur propre entité politique. Cet article propose une ethnographie des ressorts de la militarisation à Chypre du Nord et une redéfinition anthropologique de la souveraineté à partir de sa dimension spatiale. À la «reconnaissance internationale », souveraineté par l'externalité décrétée par les rapports de force entre États, il oppose une conception endogène de la souveraineté, se constituant à partir de ce que font les acteurs sociaux du territoire qu' ils revendiquent. Il montre que la souveraineté n'émerge pas par décret, mais se construit par un ensemble de pratiques sociales, politiques et militaires qui visent à dominer l'espace et à ancrer dans le temps un contrôle territorial. Les Chypriotes turcs se réfèrent à leur espace politique en parlant d'un «État créé » (uyduruk devlet), avec une connotation de fausseté et d'invention ${ }^{2}$. Mais ils évoquent aussi les procédures administratives et institutionnelles dont ils sont eux-mêmes sujets et partie prenante. La matérialisation concrète de l'existence de leur État va donc de pair avec son «invention ${ }^{3}$. La RTCN est un espace physique réel pouvant être décrit ethnographiquement, mais aussi un «État virtuel » qui se fonde sur un processus d'imagination politique.

À partir d'observations de terrain et d'entretiens avec des élites politiques et des citoyens ordinaires recueillis entre 2012 et 2014, l'article montre d'abord les ressorts de la militarisation de l'espace qui affirme et pérennise la souveraineté turque par le contrôle territorial. Il propose ensuite une étude ethnographique inédite de la militarisation aux abords de la «ville-fantôme» de Varosha (Maraş), un ancien quartier chypriote grec de Famagouste (Gazimağusa; Ammochostos), occupé par l'armée turque depuis 1974. Il illustre enfin comment la militarisation, en l'occurrence la présence de ruines de guerre, modifie non seulement les pratiques d'occupation de l'espace urbain, mais engendre aussi un impact psychosocial qui affecte durablement les représentations des acteurs sociaux. La domination de l'armée turque ne s'exerce ainsi pas seulement par

1. Pegg, 1998, p. 26.

2. NaVAro-Yashin, 2010, p. 128.

3. НовSBAWм \& RANGeR, 1983. 
le contrôle territorial et la surveillance militaire, mais aussi par le maintien de représentations liées au conflit et associées à la peur, au désir de protection et à des sentiments d'isolement et de malaise.

\section{Contrôle de l'espace et souveraineté}

Les africanistes ont montré le caractère parfois très « artificiel » de la souveraineté. Les exemples abondent d'États (Centrafrique, Somalie, Géorgie, etc.) qui peinent à imposer leur monopole de la violence sur le territoire dont ils sont formellement garants, et qui ne sont en fait «souverains» que parce que la communauté internationale veut bien leur reconnaître cette qualitét. Pour Robert Jackson et Charles Rosberg, l'accent du paradigme sur la reconnaissance et les rapports de force internationaux a imposé une conception «juridique » de la souveraineté, au détriment d'une conception «empirique » fondée sur la capacité concrète à contrôler l'espace 5 . Cette seconde conception demeure pourtant privilégiée par Carl Schmitt pour qui «est souverain celui qui décide de la situation exceptionnelle $\gg^{6}$. Giorgio Agamben considère aussi que le monopole de la décision dans les «situations d'exception » traduirait son existence concrète?

À rebours des approches juridico-formelles de la souveraineté, l'anthropologie politique nous enseigne qu'elle est d'abord « un champ de pratiques », un travail d'appropriation de l'espace et de redéfinition de ses attributs matériels sur un territoire. Pour le philosophe politique Paul Hirst, « les espaces interagissent avec et sont construits par des formes de pouvoir politique, de conflit armé et de contrôle social. L'espace est une ressource pour le pouvoir ${ }^{8}$. $\gg$ Dans Sacred Landscape (2002), Meron Benvenisti étudie les méthodes cartographiques utilisées par l'État d'Israël afin de modifier les anciens noms arabes des zones palestiniennes occupées et montre comment cette redéfinition des toponymes participe de l'exercice de sa domination. Dans Facts on the Ground (2002), Nadia Abu El-Haj montre aussi l'interdépendance entre l'utilisation de projets architecturaux, de l'archéologie, d'instruments cartographiques et de procédés juridiques avec l'objectif politique de défense et d'extension d'une souveraineté territoriale.
4. Messiant, 2008 ; Debos, 2013.
5. JACKSON \& ROSBERG, 1982, p. 1-24.
6. Sснмiтt, 1922, p. 16.
7. Agamben, 2002, p. 16.
8. Hirst, 2005, p. 13. 
L'école de Chicago et ses travaux d'écologie urbaine ont bien montré que l'espace est non seulement perpétuellement « réinventé » par les processus de labellisation et les transformations entreprises par les acteurs sociaux, mais qu' $i$ affecte lui-même ses propres acteurs ${ }^{9}$. Le géographe Kevin Hetherington nous invite de même à repenser la «matérialité des lieux », la manière dont un espace influence les représentations des acteurs qui le constituent ${ }^{10}$. L'anthropologue Éric Hirsch considère aussi que la signification d'un «paysage » demeure une construction sociale: un même lieu ne sera pas appréhendé de la même manière par des acteurs sociaux issus de contextes culturels distincts. Il appelle donc à étudier les pratiques quotidiennes des acteurs sociaux dans leurs espaces physiques et l'évolution des représentations qu' ils s'en font ${ }^{11}$. Dans La vie au guichet (1999), Vincent Dubois montre les rapports de domination qui existent au guichet de la CAF, les formes de résistance à cette domination, et le fait que la bureaucratie d'État «produit» des émotions diversifiées sur ses usagers. L'anthropologie politique a ainsi souligné la dimension «affective» de l'État, en tant que producteur de sentiments et d'affects (nostalgie, humiliation, etc.) sur ses agents et sujets.

Dans le sillage de ces recherches, cet article montre comment la militarisation de l'espace entreprise par l'armée turque depuis 1974 à Chypre du Nord participe au maintien de sa domination sur ce territoire contesté. En construisant des casernes et des postes militaires, en « turquifiant » les toponymes des localités, en interdisant l'accès à certaines zones rurales converties en camps d'entraînement et en affirmant son contrôle et sa surveillance, l'armée turque instaure durablement sur le terrain sa puissance souveraine pourtant non reconnue. La militarisation de l'espace joue un rôle concret, mais aussi performatif: elle «fait exister»la « RTCN » en excluant les autorités, les institutions, et les lois de la République de Chypre de toute interférence sur les procédures institutionnelles internes de l'entité et les pratiques sociales des Chypriotes turcs. Elle modifie donc directement les perspectives de sortie du conflit, en rendant plus improbable le retour au statu quo ante bellum désiré par les Chypriotes grecs et plaidé par la communauté internationale. J'étudie enfin comment la modification des propriétés matérielles et de l'espace physique engendre un impact psychosocial sur les représentations et le ressenti des Chypriotes turcs à l'égard de leur territoire.

9. GRAFMEYER \& JoSEPH, 1979.

10. Hetherington, 1998, p. 20.

11. HirsCh, 1995, p. 1-30. 


\section{Frontière et logiques de contournement}

En traversant le checkpoint du Ledra Palace, on constate la prégnance d'une symbolique de la souveraineté et de la militarisation. Un écriteau «Bienvenue en RTCN » accueille le visiteur en anglais et en turc. Le checkpoint lui-même symbolise l'ambivalence de la souveraineté autoproclamée. Le slogan « Vous entrez maintenant dans la République souveraine » illustre une volonté performative de «créer » une frontière. La devise «RTCN pour toujours » marque la revendication du caractère durable de l'entité politique. Le «point de contrôle de police » (Polis kontrol noktasi) impose un examen des papiers d'identité. Il implique des réponses aux questions des policiers chypriotes turcs qui arborent l'insigne « police aux frontières ». Par ces contraintes et ces rituels administratifs, on donne à voir une frontière qui démarque l'entrée dans un espace social distinct. Mais cette frontière est aussi illusoire puisqu'elle s'inscrit dans un espace physique insulaire commun. Elle demeure partielle, à l'image du « passeport » de la RTCN qui ne joue pas sa fonction, puisqu'il permet seulement aux Chypriotes turcs de voyager en Turquie. Le « visa » exigé n'est qu'un petit papier blanc tamponné à chaque passage par la police, sur lequel les Chypriotes turcs griffonnent leurs nom, prénom et numéro de carte d'identité, et qu'ils s'empressent de jeter par terre à leur retour du sud de l'île. Les mines des uns et des autres traduisent une profonde lassitude à l'égard de ces contrôles. Certains cyclistes ne prennent pas la peine de descendre de leur vélo et s'appuient sur le guichet en attente du précieux sésame, comme pour mieux forcer la main aux douaniers, et convertir symboliquement cette frontière en un simple arrêt de passage de leur trajet. D'autres, agacés, cherchent à obtenir leur tampon au plus vite. Les piles qui s'amoncellent au pied du guichet, - papiers qui sont jetés comme des tickets dans un PMU, puis balayés chaque soir -, montrent bien les usages de dépréciation des Chypriotes turcs à l'égard de ce document autant nécessaire que contesté.

Malgré l'ambivalence des documents «officiels» censés attester la souveraineté de la RTCN, son territoire constitue indéniablement un espace de contrôle social. De 1974 à 2003, les Chypriotes turcs ont vécu dans un territoire coupé physiquement du Sud et isolé internationalement. L'aéroport d'Ercan n'est pas reconnu et seuls des vols de Turkish Airlines ou de Pegasus Airlines en transit par Istanbul desservent le territoire depuis l'Europe. Comme le note le géographe Olivier Clochard, à partir du 23 avril 2003, six points de passage ont été ouverts progressivement: deux à Lefkosia/Lefkoşa (Aghios Demetios/Metehan pour les voitures et piétons et au Ledra Palace pour les piétons uniquement); à partir des bases militaires britanniques à Aghios Nikolaos/Strovilia et Pyla/ Pergamos près de Dhekelia; et enfin à Astromeritis/Zodeia («Zodhia » ou 
«Bostanci » en turc) ${ }^{12}$. Depuis le 3 avril 2008, après un accord le 21 mars entre Dimitris Christofias et Mehmet Ali Talat, un autre passage fortement symbolique a été créé pour les piétons au centre de la vieille ville de Nicosie sur la rue Ledra. Environ 30000 Chypriotes turcs traversent aujourd'hui chaque jour la ligne de démarcation (que les Turcs ne peuvent pas franchir) pour travailler ou rendre visite à des connaissances. La liberté de circulation des Chypriotes turcs demeure toutefois entravée au sein même de la «RTCN», dont l'armée turque s'est approprié des pans entiers.

La «ligne verte» (ligne «Attila» pour les Turcs) créée dès 1964, d'une longueur de $180 \mathrm{~km}$ et d'une superficie de $346 \mathrm{~km}^{2}$ depuis la partition de 1974, ce no man's land démilitarisé et contrôlé par les Casques bleus de l'UNFICYP, ne constitue que l'aspect le plus connu de la militarisation de l'île. Cet espace de démarcation prit peu à peu forme dès l'envoi d'une force de maintien de la paix de 2500 hommes, le 27 mars 1964, conformément à la résolution $186 \mathrm{du}$ Conseil de sécurité de l'ONU qui instaura un cessez-le-feu entre les milices de l'EOKA-B et de la TMT après les heurts intercommunautaires du « Noël sanglant » qui entraînèrent 184 victimes (dont 108 Chypriotes turcs) entre le 21 et le 30 décembre 1963 à Kaymakli, Mathiatis, Lapithos et Vasileia. Ces heurts et la découverte d'un charnier de 21 Chypriotes turcs à Aghios Vasileios marquèrent une profonde rupture entre les deux communautés et le début de la partition physique du territoire ${ }^{13}$. L'armée turque renomma ensuite ce mur de séparation «ligne Attila », du nom du commandant Attila Sav qui dirigea les forces armées turques lors du débarquement de 1974. Cette zone au sein de laquelle aucun civil n'a accès ni ne peut circuler se trouve elle-même « surveillée » par les policiers chypriotes grecs et «contrôlée » par l'armée turque, qui a érigé un mur supplémentaire de séparation.

12. Clochard, 2008, p. 80.

13. Drevet, 2000, p. 141. 


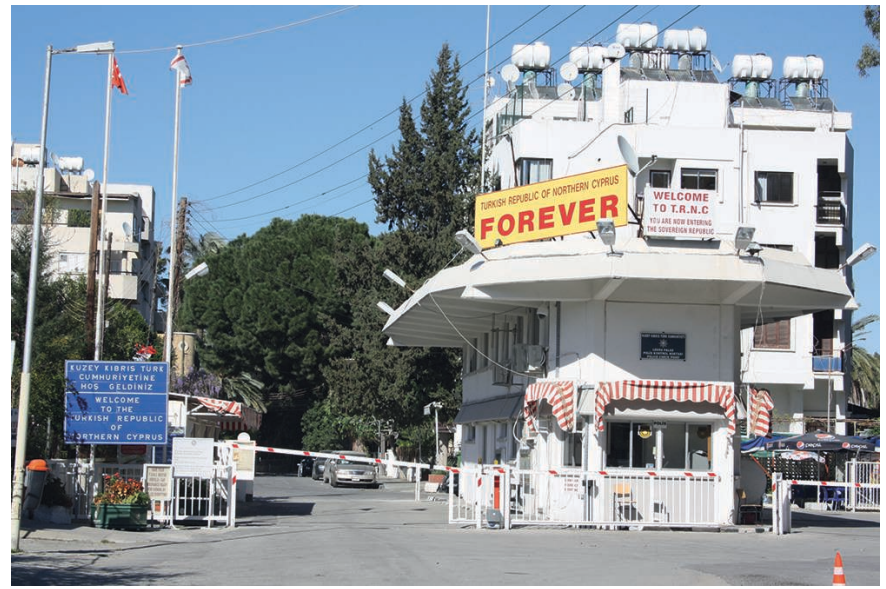

PHOTO 1. CHECKPOINT À LEFKOŞA/NICOSIA

(C) Mathieu Petithomme

Les pratiques concrètes des acteurs le long de cette zone tampon en disent long sur le rapport qu'ils entretiennent avec cette frontière. Que ce soit au point de passage du Ledra Palace ou à celui de la rue Ledra, les policiers chypriotes grecs restent à l'intérieur de leur guérite et ne contrôlent que certaines personnes. Le plus souvent, ils font seulement signe aux piétons qu' ils observent uniquement de loin derrière la fenêtre de montrer rapidement leurs papiers d'identité et leur «visa ». Il est aussi possible de passer sans aucun contrôle. À l'inverse, il n'est pas rare d'observer de longues files d'attente à l'entrée de la RTCN pour obtenir le tampon donnant droit de passage: les policiers chypriotes turcs prennent leur temps, tournent soigneusement les pages des passeports, vérifient sur leur ordinateur, entrent les numéros d'identification et examinent les tampons antérieurs, voire même posent parfois quelques questions. Là où les pratiques des policiers chypriotes grecs illustrent leur refus de reconnaître une frontière qui pour eux n'a pas lieu d'exister, celles des policiers chypriotes turcs traduisent au contraire une volonté de matérialiser la frontière, d'affirmer son existence par des pratiques bureaucratiques, même si elles sont considérées par les Chypriotes turcs comme profondément inutiles, chronophages et fastidieuses. 


\section{Quadrillage du territoire et omniprésence du contrôle policier}

«Zone interdite» (Yasak Bölge Girilmez) constitue l'injonction la plus visible de l'espace physique de la RTCN, accompagnée du buste militaire noir sur fond rouge qui surplombe cet écriteau. Il a même, d'une certaine manière, pénétré l'inconscient des Chypriotes turcs, qui évitent de circuler autour des postes militaires, et vous invite à «ne pas regarder dans leur direction». Les baraques, postes de contrôle et autres zones d'entrainement de l'armée grèvent le territoire physique. Des slogans peints sur les murs des camps militaires tels que «Tire, tue et soit fier », «Heureux soit celui qui est turc» ou «La loyauté à notre armée est notre honneur » imprègnent l'espace d'une iconographie militariste et nationaliste. Des barbelés érigés au milieu des champs fournissent un caractère tangible à la militarisation. Des bustes d'Atatürk et les drapeaux turc et chypriote turc ornent les places de chaque ville et village. L' «empreinte physique»de l'armée turque est ainsi visible dans la plupart des espaces urbains et ruraux. Des villages abandonnés par les Chypriotes grecs ont été entièrement convertis par l'armée en casernes.

Lors de la partition, de nombreuses églises orthodoxes ont été pillées et des cimetières profanés, pour porter atteinte à la mémoire de l'autre ${ }^{14}$. L'armée turque soutint alors une économie du pillage (ganimet) des biens des déplacés, donnant corps à la classe sociale des «nouveaux riches de 1974 » ou des « ganimettos ${ }^{15}$ 》. Les zones résidentielles sont de même souvent entourées de baraques militaires. À Lefkoşa, les habitants des quartiers Selimiye, Yenicami et Çağlayan côtoient quotidiennement la Ligne verte et ont appris à vivre avec le sentiment d'être observés en permanence par les soldats turcs en faction sur leurs miradors verts et blancs. Ceux qui vivent dans l'ancien quartier arménien Arabahmet peuvent observer les commerces chypriotes grecs depuis le «parc de la frontière», le Sinır Parkı (aussi nommé «l'endroit des courageux», Yiğitler Burcu Parkı), un petit espace de verdure entouré de grillages et contrôlé par une baraque militaire adjacente. Ils peuvent aussi jouer au football sur le stade voisin sous le contrôle du mirador de l'UNFICYP, tout en observant les Chypriotes grecs transiter de l'autre côté des barbelés.

À Girne (Kyreneia), Özer, un serveur, m’a appris que la musique a été interdite après $22 \mathrm{~h}$ dans les bars et les restaurants touristiques du port pour ne

14. Copeaux \& Mauss-Copeaux, 2005, p. 50-73.

15. Navaro-Yashin, 2012, p. 30-32. 


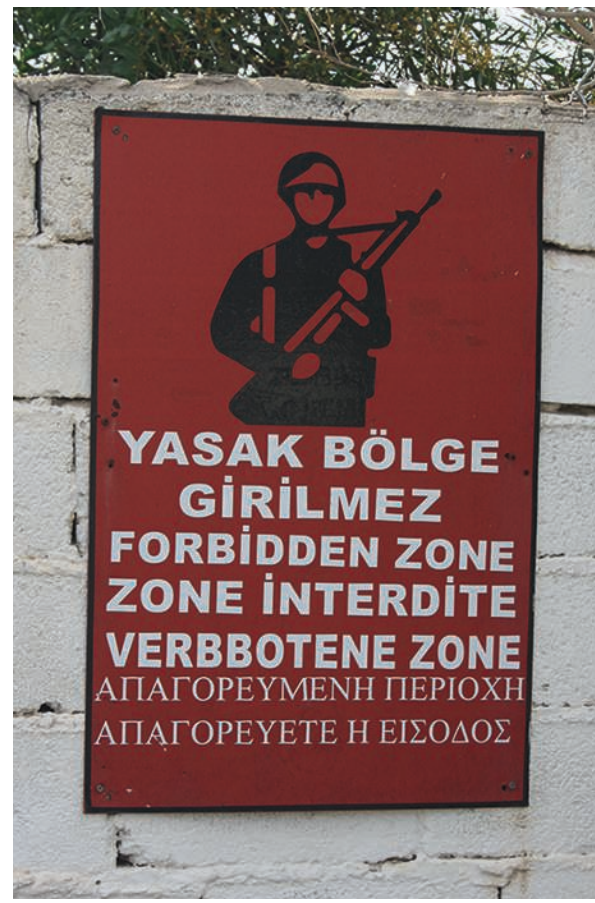

PHOTO 2. «ZONE INTERDITE »

Avec faute d'orthographe en allemand et en grec...

(C) Mathieu Petithomme pas déranger le repos des militaires de la caserne environnante ${ }^{16}$. À Gazimağusa (Ammochostos), le quartier Canbulat de la plage ressemble à un village militaire: on y croise plus d'hommes en armes que de civils. L'école, les terrains de sport et les quelques commerces sont encerclés par les casernes et les immeubles où résident les soldats. À l'entrée de la ville, au nord du boulevard İsmet Inönü, l'immense caserne Gülseren Kişlasi occupe et interdit l'accès au littoral sur plus de $2 \mathrm{~km}$. À Lefke (Lefka), en plein centre-ville, un champ de tir pour des entraînements militaires se dresse en face d'immeubles résidentiels. Le quadrillage du territoire et l'omniprésence du contrôle sont aussi ressentis par la présence de la force de sécurité de la RTCN (KKTC, Güvenlik Kuvvetleri Komutanlı̆̆ı) et celle de la police, composées chacune d'environ 5000 membres. La force de sécurité

de la RTCN est une division militaire composée de Chypriotes turcs sous le contrôle de l'armée turque et de son État-major. Elle se charge de la formation des soldats locaux et de la police chypriote turque; son Major-Général est nommé par l'armée turque depuis 1976 pour un mandat de deux ans. De plus, même si les condamnations sont désormais assez rares, les accusations de « menace à la sécurité de l'État » ou d' « incitation à la haine de l'armée » sont parfois utilisées contre les militants de la paix et les journalistes qui, tels que Şener Levent, éditorialiste du quotidien Afrika Gazetesi (La Gazette de l'Afrique), ou Alpay Durduran et les membres du Parti de la Nouvelle Chypre (Yeni Kıbrıs Partisi, YKP), dénoncent l'« occupation » (İsğal) de l'armée turque. Pour un officier turc, être nommé à Chypre représente une promotion enviable puisque sa solde est doublée et que le

16. La liste détaillée des entretiens est disponible en fin d'article. 
Politique et sociétés à Chypre aujourd'hui

climat et la tranquillité qui règnent donnent à de nombreux militaires l'impression d'être dans un camp de vacances. Un lieu où ils peuvent faire valoir leur toutepuissance, imposer des contrôles routiers impromptus, surveiller et intimider les militants pro-réunification.
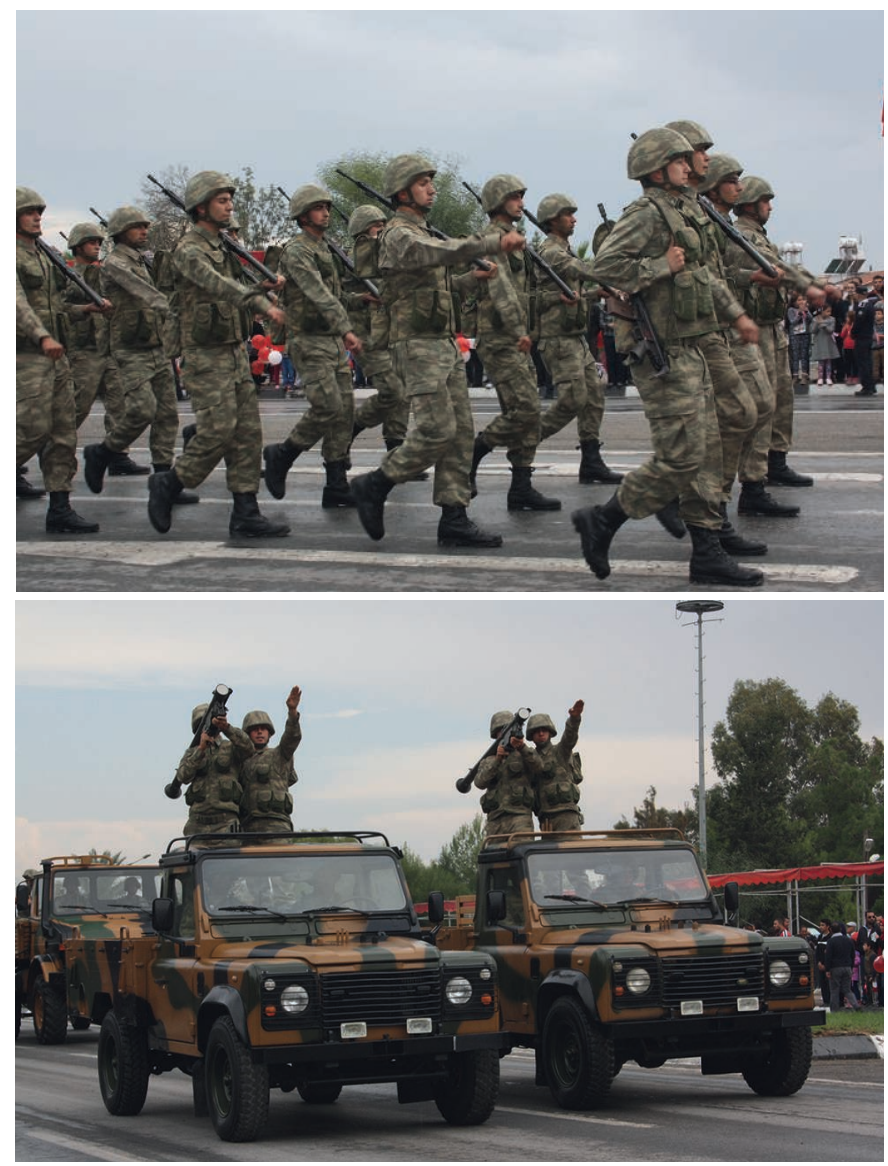

\section{PHOTO 3A ET 3B. PARADE MILITAIRE LORS DES CÉLÉBRATIONS \\ DE « L'INDÉPENDANCE » DE LA RTCN, 15 NOVEMBRE 2014 \\ () Mathieu Petithomme}

À partir du vendredi après-midi, la vieille ville de Lefkoşa se transforme en un véritable parc de loisirs pour militaires en permission. Les commerces ont été modifiés pour répondre à leurs besoins: magasins de téléphonie mobile pour recharger leurs cartes et appeler leurs proches en Turquie; vendeurs de jeans et 
de tee-shirts à la mode; cafés et döners turcs; boutiques de jeux et de paris en ligne. Huseyin, un militaire turc de 25 ans, rencontré sur la place Ismet Inönü, près de la porte de Girne à Lefkoşa, me dit à ce propos: «Lors de nos permissions, comme il n'y a rien à faire, nous venons sur la place et nous discutons. C'est pour ça qu'il y a plein d'hommes, que des militaires presque! » En proie à un certain malaise face à cette masculinisation et à cette turquification de l'espace urbain, les commerçants chypriotes turcs ont progressivement déserté les lieux depuis les années 1980. La classe moyenne locale a aussi préféré accéder à la propriété dans les quartiers de Küçük Kaymakli, de Kizilay ou d'Ortaköy de la partie moderne de la ville, ou dans des villas toutes équipées dans les villes adjacentes de Gönyeli, d'Hamitköy et de Haspolat. En recherche de logements à bas prix, les immigrés turcs travaillant comme ouvriers dans le secteur du bâtiment ou comme saisonniers dans celui de l'agriculture repeuplèrent alors le centre-ville, en occupant souvent sans le savoir les maisons abandonnées par les Chypriotes grecs ou en louant des biens à la nouvelle bourgeoisie chypriote turque. La présence quotidienne dans l'espace social d'environ 30000 militaires, épaulés par la force de sécurité et les policiers chypriotes turcs sous tutelle de l'État-major, renforce le sentiment d'être surveillé en permanence. Si l'on rapporte les effectifs militaires et policiers (environ 40000 ) à la population totale, estimée à 294806 habitants selon le dernier recensement de 2011, une personne sur sept est donc directement issue des forces de sécurité. Cette «policiarisation» de l'espace social pour reprendre l'expression de Béatrice Hibou ${ }^{17}$ va aussi de pair avec une dépendance socioéconomique de nombreux habitants à l'égard des forces de police: dans le contexte de l'embargo économique du territoire, la police (comme les autres administrations) joue aussi une fonction sociale en donnant accès à des emplois publics dans un marché du travail réduit. Constituée exclusivement de Chypriotes turcs, elle est mieux perçue que l'armée turque, critiquée pour les excès de zèle de certains de ses officiers. Les Chypriotes turcs cherchent à exploiter leurs réseaux (torpil) afin d'y entrer et d'accéder à une source stable de revenus.

L'omniprésence des forces de sécurité débouche sur le sentiment que l'armée turque constitue le réel «souverain», dans la mesure où le gouvernement local élu démocratiquement doit composer avec sa présence physique et ses interférences politiques. Ismail, gérant turc de la petite pension Seslikaya, rue Asmaalti à Lefkoşa, considère ainsi que «l'armée turque fait à peu près ce qu'elle veut ici. Si le gouvernement de Turquie voulait arrêter de soutenir la RTCN, l'armée s'y opposerait. » Pour Murat Kanatli, secrétaire général du YKP, «les politiques ne peuvent rien, c'est l'armée qui tire les ficelles. Elle tire

17. Нiвоu, 2006, p. 98. 
aussi profit économiquement de l'occupation, par exemple en contrôlant et en exploitant pour son compte le port de Famagouste. » Le point de vue de Kemal, un militaire turc, illustre ce sentiment de toute-puissance de l'armée. En réponse à la question très simple «Qui gouverne ici? », il répondit: «C'est l'armée bien évidemment! Le gouvernement d'ici ne peut rien sans nous! La sécurité, c'est nous qui l'assurons. L'économie, c'est nous qui la finançons. Tout dépend de l'armée. Ils organisent un peu les choses ici, mais au fond, c'est l'armée qui décide. » Les Chypriotes turcs ont donc dû s'accommoder à cette présence. À l'école, ils chantent l'İstiklâl Marşı, l'hymne national de la RTCN (et de la Turquie), et célèbrent aussi la «mère-patrie» (ana-vatan) et la gloire d'Atatürk. L' « Anniversaire de la Grande Victoire» (Büyük Zafer Bayramı) contre l'armée grecque le 30 août 1922, ou encore le «Jour de la République» (Cumburiyet Bayramı) qui célèbre la fondation de la République de Turquie le 29 octobre 1923, sont autant de jours fériés en Turquie et en RTCN, commémorés de façon enthousiaste par les nationalistes à Chypre du Nord par des défilés militaires ${ }^{18}$. Mais la plupart des Chypriotes turcs boudent ces cérémonies qui illustrent surtout pour eux le maintien d'une « situation d'exception » caractérisée par l'isolement diplomatique et l'embargo économique.

\section{Varosha (Maraş) : ethnographie d'un espace militarisé en ruines}

Un exemple paradigmatique de cette militarisation de l'espace est donné par les ruines de Varosha (Maraş), un ancien quartier et station balnéaire de Famagouste peuplée avant 1974 par 37000 Chypriotes grecs dont 6000 à Varosha. J'ai enquêté autour de cette «ville fantôme» en mars 2014, photographiant les bâtiments (malgré les interdictions), cherchant à m'imprégner des lieux et questionnant les habitants des alentours sur leurs sentiments à l'égard de ces ruines. Ce travail ethnographique permet de comprendre comment un espace physique militarisé et en ruines « produit » des affects et des émotions sur les citoyens en les renvoyant à l'imaginaire du conflit et à la nostalgie du passé pour les plus anciens. Famagouste est une ancienne ville vénitienne fortifiée. Les Chypriotes turcs ont résidé jusqu’à ce jour dans ce qui subsiste de l'ancienne Famagouste, qui avait été démontée pierre par pierre après la conquête ottomane en 1571. La population chypriote grecque vécut quant à elle jusqu'en 1974 dans la partie moderne de la ville, désignée sous le nom de Varosha, qui fut l'une des plus belles plages d'Europe. À quelques heures des capitales européennes, la blancheur et la finesse du sable de Varosha n'avait d'égal que dans les îles lointaines.

18. Papadakis, 2003, p. 263. 
Au début des années 1970, Famagouste était l'endroit où «il fallait être », la destination touristique numéro un et le principal port de marchandises et de passagers de Chypre. Avec ses immeubles modernes longeant le front de mer, le quartier de Varosha bâti en 1972 le long de la plage de Glossa fut rapidement renommé pour ses grands hôtels, dont le King George, l'Asterias, le Florida ou encore le Grecian. L'hôtel Argo, au bout de l'avenue John Fitzgerald Kennedy, qui se tourne vers la plage de Kalamis puis la baie du figuier de Protaras, accueillit des vedettes, dont l'actrice britanno-américaine Elizabeth Taylor. Le Golden Sense vit passer Paul Newman et Sophia Loren. Les bars, restaurants et boîtes de nuit de la rue Leonidas furent plébiscités par des célébrités comme Richard Burton, Raquel Welchet et Brigitte Bardot. Mais la totalité de ses habitants a fui la ville le 15 août 1974 vers Paralimni, Deryneia et Larnaca, lorsque l'armée turque entra dans Famagouste et convertit Varosha en une zone tampon abandonnée, susceptible de constituer un territoire clé lors d'un éventuel échange territorial.

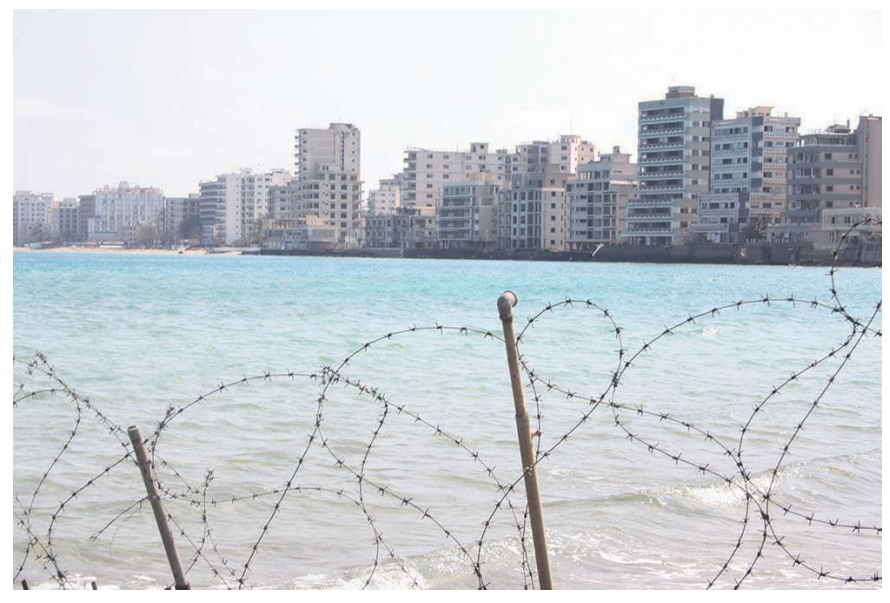

\section{PHOTO 4. RUINES DE VAROSHA (MARAŞ) \\ DEPUIS LA PLAGE DE GAZIMA $\breve{G}$ USA (AMMOCHOSTOS) \\ (C) Mathieu Petithomme}

Les réfugiés chypriotes grecs ont reconstruit leur capitale de province à Paralimni, aujourd'hui peuplée d'environ 15000 habitants. Lorsqu'elle prit le contrôle de la cité d'environ $10 \mathrm{~km}^{2}$, l'armée turque clôtura l'espace de barbelés et de grillages et l'État-major ordonna aux soldats de tirer sur toute personne qui chercherait à y pénétrer. La cité s'étend selon mes calculs sur $8,8 \mathrm{~km}$ le long du littoral et sur 5,4 km dans les terres pour une largeur de 1,3 $\mathrm{km}$ au nord et de $3,5 \mathrm{~km}$ 
138 Politique et sociétés à Chypre aujourd'hui

au sud. La résolution n 550 du Conseil de sécurité de l'ONU du 11 mai 1984 considéra «illégal le contrôle de la zone par l'armée turque », stipulant que « les personnes déplacées en 1974 doivent pouvoir regagner leurs lieux de résidence. » Lors des négociations de paix du début des années 2000, les dirigeants chypriotes turcs acceptèrent la perspective d'un retour des déplacés de Varosha, qui fut incluse dans le plan Annan, ce qui demeura sans effet après le rejet de celui-ci par 75,8 \% des Chypriotes grecs le 24 avril 2004 ${ }^{19}$. En 2010, Okan Dagli et Mertkan Hamit, deux Chypriotes turcs de Gazimağusa, formulèrent une proposition visant à rendre Varosha et à la convertir en une ville écologique. Lors de notre entretien, Mertkan justifia ce projet :

Depuis 40 ans, nous vivons à côté de cette ville fantôme. Cela a un impact négatif sur notre moral et notre société. La jeune génération chypriote turque est confrontée aux conséquences de cet isolement et de la division de l'île qui ont beaucoup d'inconvénients. Rendre Varosha aux Chypriotes grecs et la convertir en une ville bicommunautaire et écologique serait un exemple pour la paix et la réconciliation.

Mais le projet se heurte à la ferme ambition de l'armée turque de se maintenir sur place de même qu'à l'absence de volonté politique des dirigeants chypriotes grecs et turcs de trouver un compromis. Sur le terrain, les ruines de la « Tour Twica » ou de l' «hôtel de Kyrenia » se dressent juste derrière la plage du centre-ville de Gazimağusa, derrière un grillage barbelé protégé par une toile verte opaque. Le sable est certes fin et l'eau de la Méditerranée bleu translucide, mais les baigneurs sont rares, tant le sentiment de malaise est intense. Comme le relèvent les journalistes Pauline Chanu et Christophe Gleizes, « la situation relève de l'absurde », puisqu'à seulement quelques mètres des barbelés et des ruines dont il est difficile de détacher son regard, «les familles en villégiature se baignent sous l'œil vigilant et inquisiteur des militaires turcs » (2014). Plus que le repos et la détente, la plage suscite l'incompréhension, la tristesse, et le sentiment d'un immense gâchis. Le contact physique et visuel avec des ruines si imposantes donne un caractère tangible aux idées de «conflit» et de «déplacement de populations ». La «ville fantôme» de Varosha (Maraş) témoigne et traduit physiquement ce que la partition (taksim) veut dire.

Autour des ruines, en l'absence de l'homme, la nature a repris ses droits. Dans Homo Disparitus, Alan Weisman décrit comment les immeubles se sont dégradés, les végétaux ont poussé (philodendrons sauvages, hibiscus, bougainvilliers, etc.),

19. AKÇALI, 2009, p. 196. 


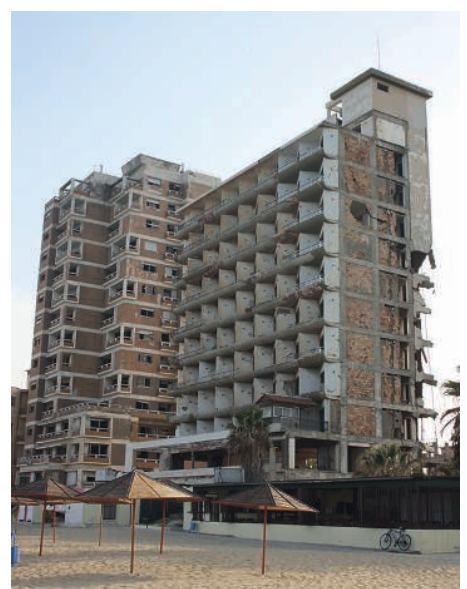

PHOTOS 5A, 5B ET 5C. ASPELIA HÔTEL,

TWICA TOWER ET UN AUTRE HÔTEL EN RUINE, VAROSHA

(c) Mathieu Petithomme

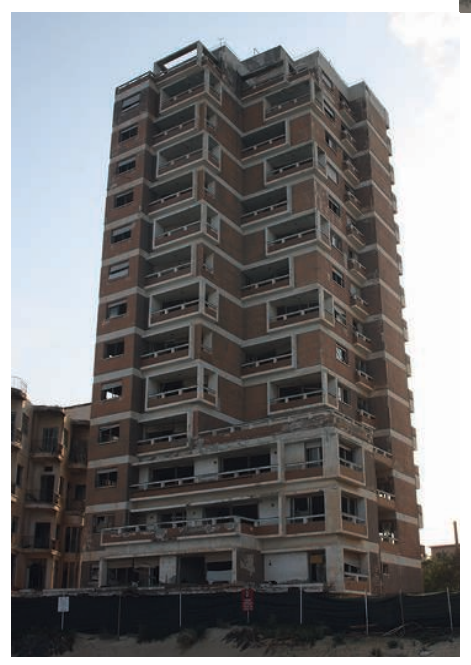

et l'espace a été reconquis par les oiseaux et les tortues ${ }^{20}$. L'armée a réparti ou vendu les biens laissés par les Chypriotes grecs dans leur fuite: portes, argenterie et couverts des hôtels, fauteuils des salons, meubles des appartements, marbres des allées piétonnes. Les voitures de luxe, Cadillac ou autres Mercedes abandonnées firent la joie des chefs de l'État-major. Le pillage (ganimet) des biens des déplacés fut encouragé par les généraux et favorisa l'enrichissement rapide des militaires présents. Puis l'armée nettoya les routes limitrophes et créa des postes

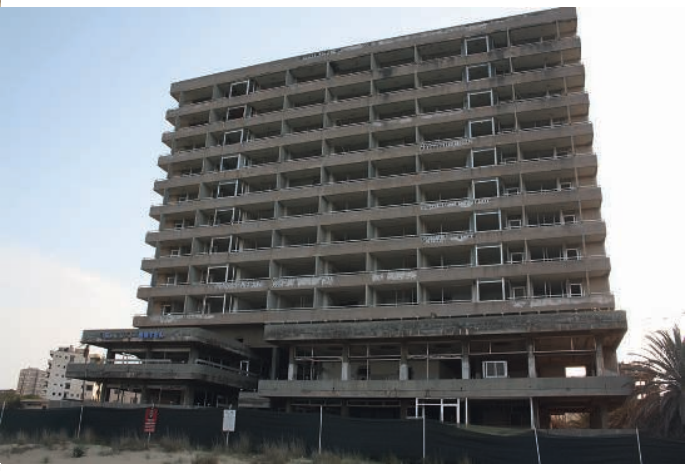

de contrôle. La cité n'est désormais plus que débris. Les hôtels tombent en ruines et sont rongés par l'érosion. L'accès à l'ensemble du littoral maritime est interdit et peut impliquer la cour martiale et une peine d'emprisonnement. Du haut de leur guérite, par des sifflets, les soldats turcs dissuadent les visiteurs de s'approcher ou de photographier la zone. L'appropriation de Varosha a aussi renforcé la militarisation du reste de la ville de Gazimağusa. Lorsque les jeunes Chypriotes turcs jouent dans la cour du collège turc de Famagouste (Gazimă̆usa Türk Maarif Koleji) ou sur les courts de tennis environnants (Tenis Kulübü Tesisleri), ils voient

20. Weisman, 2007, p. 126. 
quotidiennement les ruines. Les habitants des quartiers Harika et Canbulat vivent aussi avec leur proximité: «On fait tous semblant de ne pas les voir », me dit Akif, un serveur turc du Blue Lagoon originaire de Mersin. Le bar tendance Red Room Plus à l'angle de la rue Kemal Server a fermé en 2013 : il suffisait de traverser la rue depuis sa petite terrasse pour se trouver nez à nez avec les barbelés. Difficile pour les clients de penser à autre chose sur les tubes de la musique pop turque en face de ruines qui remémorent les souffrances du passé et le statu quo du présent.

De la pelouse du stade de football Fazil Küçük (Fazil Küçük Stadyumcu), on observe l'imposante église orthodoxe de l'ancien quartier chypriote grec, située entre les rues Samou et Thrakis. Mais derrière le stade, autour de l'église, environ $500 \mathrm{~m}^{2}$ de terrain ont été convertis en une grande caserne. La symbolique du lieu renvoie à la réalité de la militarisation : l'armée turque encercle et interdit l'accès au plus beau monument orthodoxe de Famagouste qui demeure cependant visible et incontournable pour n'importe quel observateur. En remontant la rue Hasan Yusuf Arseven vers le centre-ville, une autre caserne occupe l'ensemble de la partie ouest de la rue. Les appartements Hüseyin Erler situés plus au nord logent exclusivement des militaires et leurs familles. En face, sur la rue Havva Şentürk Yolu, un homme en armes surveille en permanence le pont d'entrée de l'«île de Jerry », sur laquelle se dresse une maison abandonnée d'architecture coloniale, et qui débouche par un bras de terre sur un autre îlot, « la Grande Île » (Büyük Ada). En continuant sur les avenues Canbulat puis Yeşil Deniz, on trouve une autre caserne puis le port de Famagouste (Gazimăgusa Limani), interdit aux visiteurs et dédié au transport de marchandises, illustrant l'importance du « complexe militaro-économique », l'imbrication du rôle de contrôle de l'armée avec sa mainmise sur l'import-export et les activités économiques. Seul un petit quai permet aux bateaux de voyageurs en provenance de Turquie d'accoster. Dans ces lieux comme dans de nombreux autres endroits de Chypre du Nord, la militarisation de l'espace n'est pas seulement une réalité physique tangible, elle affecte aussi les représentations et le ressenti des Chypriotes turcs. 

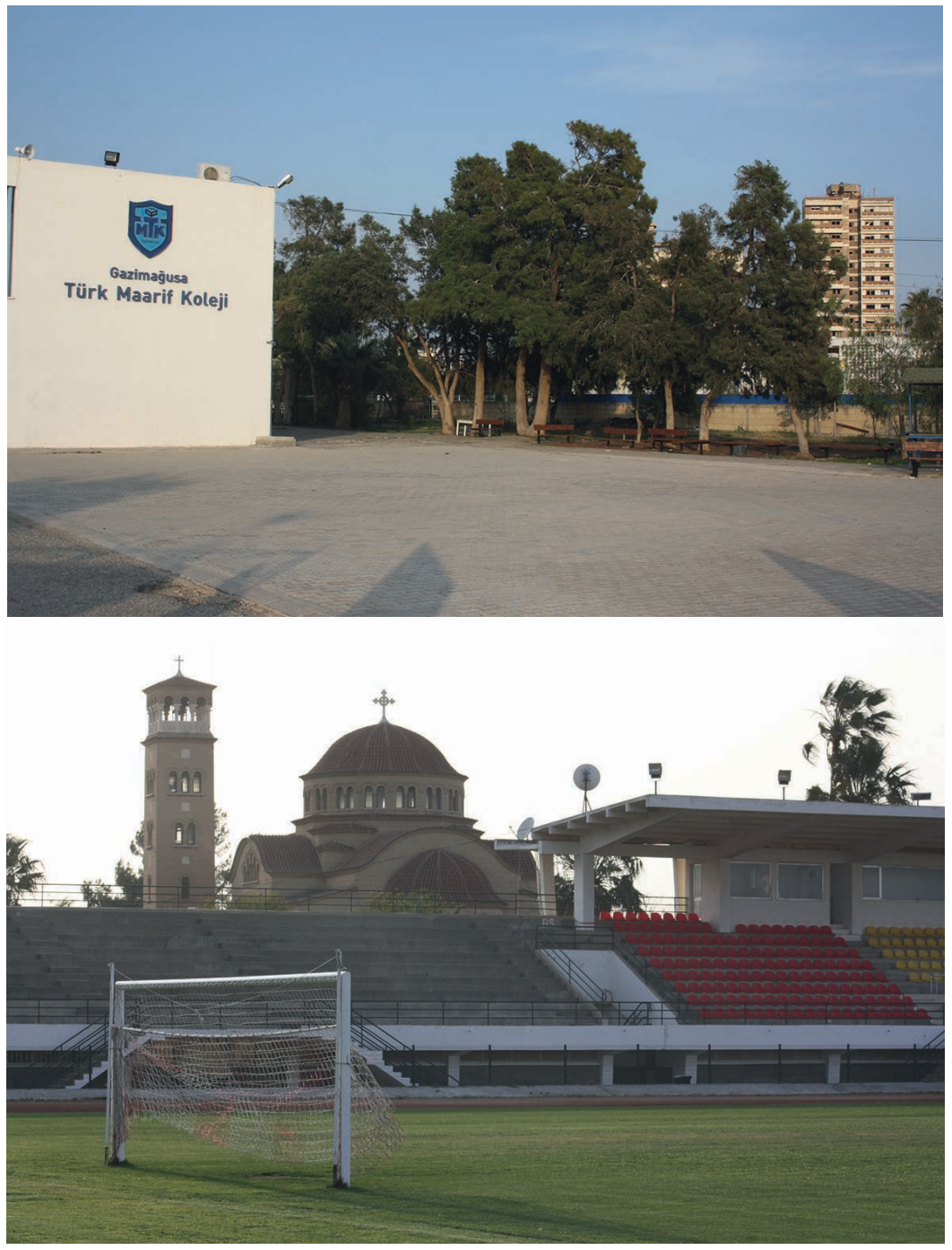

PHOTOS 6A ET 6B. COLLÈGE TURC ET STADE FAZIL KÜÇÜK STADYUMCU AVEC VUE SUR L'ÉGLISE ORTHODOXE OCCUPÉE, GAZIMAĞUSA

(c) Mathieu Petithomme 


\section{L'impact psychosocial de la militarisation \\ Du sentiment d'insécurité au désir de protection militaire}

L'élément fondateur des attitudes des Chypriotes turcs à l'égard de l'armée turque est lié au maintien d'un sentiment d'insécurité résultant de leur condition minoritaire, de leur isolement international et de l'absence de soutiens extérieurs, hormis celui de la Turquie. Ce sentiment d'être «seuls contre tous », après avoir été attaqués par les Grecs et les Chypriotes grecs en 1974, constitue le socle de la justification en faveur du maintien de sa présence, comme le défend Ege, un policier proche de la retraite:

Heureusement que l'armée turque nous a défendu en 1974, parce que sinon, il n'y aurait plus de Chypriotes turcs sur cette île! Si elle partait, les Chypriotes grecs nous imposeraient leurs lois dès le lendemain! L'armée turque doit rester pour le moment jusqu'au jour où notre autonomie sera reconnue.

Mustafa, un commerçant de Lefkoşa, exprime bien ce sentiment assez partagé des Chypriotes turcs d'être livrés à eux-mêmes: «Il faut se mettre à notre place. Pour vous les Européens, c'est facile de présenter l'armée turque comme une puissance occupante. Mais pour nous, c'est notre seul soutien pour défendre notre territoire et nos droits. »

Ce sentiment d'insécurité est encore plus fortement partagé par les immigrants turcs. Pour nombre d'entre eux, il ne fait aucun doute que, sans la présence de l'armée, les Chypriotes grecs chercheraient à reprendre le contrôle du nord. Ali, agent d'accueil dans un hôtel, évoque bien ce ressenti : «Quand on tue vos femmes et vos enfants, vous faites intervenir l'armée. C'est partout pareil. Sans l'armée, les Chypriotes grecs reprendront le contrôle du nord et ne voudront plus partager. Donc il faut que l'armée reste. » La propagande nationaliste, à la télévision et dans certains journaux, exagère toutefois constamment la « menace » que représentent les Chypriotes grecs, glorifiant le rôle de «sauveur» et de «bienfaitrice» de l'armée turque. Pour Murat Kanatli (YKP): «L'armée turque ne cesse d'intimider les gens. Même s'ils ne l'aiment pas, ils ont peur de son départ. Elle fait tout pour créer un sentiment de menace, pour donner l'impression que sa présence est nécessaire. »

Dans la compréhension du désir de protection des Chypriotes turcs, un manque de confiance envers les Chypriotes grecs s'ajoute à ce sentiment d'insécurité. La propagande nationaliste cherche à imposer l'idée que le conflit trouverait ses racines dans la volonté historiquement ancrée des «Grecs» de dominer l'île sans partage. L'évincement des élites chypriotes turques des 
municipalités et des institutions bicommunautaires en 1973 à la suite à la révélation des 13 amendements de Makarios et du plan Akritas visant à subvertir la Constitution de 1960, constitue encore la toile de fond des perceptions au Nord. Les Chypriotes turcs tiennent les Chypriotes grecs pour responsables de leur marginalisation dans les enclaves à partir de 1963 et de l'éclatement du conflit en 1974. La tentative de coup d'État soutenue par la Grèce est vue comme l'élément déclencheur. Peu importe que les dirigeants de la TMT aient soutenu activement le regroupement des Chypriotes turcs dans les enclaves afin de mieux les contrôler et de propager le nationalisme turc. La volonté des généraux grecs de mettre en place par la force l'enosis, l'union avec la Grèce, est restée ancrée dans les perceptions, de telle sorte que les Chypriotes grecs sont vus comme coresponsables. Cette justification originelle est par exemple mise en avant par Tansel Doratli, vice-président du parti de la démocratie et de la confiance (Demokrasi ve Güven Partisi, DGP), une petite formation nationaliste et néolibérale: «il ne faut surtout pas oublier que l'armée turque est ici parce que les Grecs voulaient l'enosis. » Nihat, professeur d'histoire au lycée chypriote turc de Lefkoşa, ne cache pas qu'il transmet cette méfiance à ses élèves: «Je dis à mes élèves que l'armée turque est là pour protéger les Chypriotes turcs, qu'elle agit dans notre intérêt et qu'elle restera ici, tant qu'il n'y aura pas d'accord de paix. L'armée turque joue le rôle d'un garant, car nous n'avons plus confiance. »

Le sentiment d'insécurité et le manque de confiance entraînent enfin l'importance d'obtenir des garanties politiques. Le maintien de la présence de l'armée est vu par les nationalistes comme une garantie nécessaire au moins jusqu'à un hypothétique accord de paix. Parmi eux, l'idée que l'armée turque est là pour «protéger les Chypriotes turcs » fait consensus. Metin Çatan, membre du bureau du parti démocrate (DP), déclare ainsi : «L'important, ce sont les garanties que les Chypriotes grecs doivent nous donner pour qu'une fois que l'armée turque sera partie, ils n'envahissent pas le Nord. C'est encore plus vrai depuis leur rejet du plan Annan. » Pour Cüneyt Küçük, membre du bureau de l'UBP, «l'armée turque doit rester, car elle est garante de notre sécurité et qu'aucun accord de paix n'a encore été signé. » Tansel Doratli considère même qu'un certain nombre de troupes turques doit rester en RTCN, même dans le cas d'un accord de paix : « Ce nombre peut être négocié, mais l'armée turque doit rester. Les Chypriotes grecs s'appuient sur les bases militaires britanniques, nous sur la Turquie. »

Leman Aslim, conseillère auprès du gouvernement de la RTCN (KKTC Başbakanlik), partage le même avis: «L'armée turque doit rester pour notre sécurité. Un accord doit simplement porter sur la réduction progressive du nombre de troupes. Sans cela, les Chypriotes grecs voudront reprendre le contrôle du Nord. C'est une question de survie pour nous. » D'autres acteurs comme 
Tahsin Ertuğruloğlü, président du DGP et ancien membre de l'UBP, acceptent d'évoquer un retrait, mais uniquement après un accord: «Le système des garants doit être maintenu. L'armée turque ne peut pas se retirer avant que notre autonomie et notre sécurité soient reconnues par une loi constitutionnelle qui ne pourra pas être remise en cause.» Cette idée est même partagée par la gauche, comme l'illustre le propos d'Özkan Yorgancioğlü, secrétaire général du parti républicain turc $(\mathrm{CTP})$ : « Le jour où il y aura la paix, l'armée turque devra partir petit à petit. Mais il nous faut des garanties. »

\section{Un malaise palpable}

La militarisation de l'espace n'engendre pas seulement une présence physique très visible de l'armée turque, de même qu'un climat de surveillance et de contrôle des citoyens et des journalistes qui critiquent le maintien de ses contingents au nord de Chypre. Elle génère surtout un sentiment de malaise partagé par tous, qu'ils soient favorables ou non à son maintien. La militarisation produit un climat social pesant, ressenti par tous les Chypriotes turcs. Ils disent seulement pouvoir parler librement dans leurs terrasses et jardins intérieurs (avlu), par peur de la surveillance policière et du contrôle de leurs voisins. Yael Navaro-Yashin évoque ainsi les «sentiments de suffocation» ressentis par les Chypriotes turcs, qui se traduisent par un certain nombre d'expressions populaires et de métaphores synthétisant leurs expériences quotidiennes de la militarisation et du confinement: ils disent ainsi souvent vivre dans «une prison à ciel ouvert» (açik hava hapishanesi), être « enfermés à l'intérieur de ce lieu » (bunum çinde kapalı olmak), «se sentir étranglés par le cou» (boğazımızdan sıkı lıyormuş gibi hissetmek), ou encore ressentir le «maraz», un mot qui peut être traduit comme un état de mélancolie et de dépression ${ }^{21}$. À travers ses ruines imposantes et impossibles à éviter du regard, la cité fantôme « hante » les Chypriotes turcs : elle donne à voir physiquement un concentré de leurs émotions refoulées liées au conflit (la nostalgie, la tristesse et la souffrance), et le sentiment d'un immense gâchis. Il suffit de questionner les Chypriotes turcs de Famagouste pour prendre la mesure du sentiment de malaise que suscite la ville en ruine.

Ma rencontre avec Aksel et Koray, deux enseignants octogénaires à la retraite, sur la terrasse de l'hôtel Palm Beach Resort créé en 1948, qui jouxte la cité abandonnée sur la plage de Gazimağusa, m’a permis de saisir ces sentiments. Pressentant le malaise potentiel de mes interlocuteurs à évoquer la ville abandonnée, j'ai d'abord cherché à établir une relation de confiance en parlant de banalités. Maniant très bien l'anglais, ils m'ont d'abord parlé d'eux-mêmes, de

21. Navaro-Yashin, 2012, p. 16. 
leurs souvenirs et de leur travail en tant que jeunes professeurs durant le mandat colonial britannique. Ce fut seulement après quarante minutes de conversation que la question de Varosha émergea dans nos échanges, après un moment de silence symptomatique de notre malaise commun à aborder un sujet que nous observions pourtant tous du regard. A posteriori, j'eus le sentiment que notre conversation préalable n'avait été qu'une manière de respecter la mémoire des lieux et de ses anciens habitants, en esquivant un sujet grave et douloureux qui mérite respect. Ce fut Koray qui enclencha la bifurcation de notre conversation, en me voyant longuement observer la guérite des militaires turcs. De façon presque irréelle, il me demanda: «Vous avez vu les ruines? », alors même que je les observais depuis longtemps, comme eux deux d'ailleurs, et qu'il était impossible de ne pas les voir. Son interrogation fut en fait une question rhétorique, puisqu' il continua à parler après mon hochement de tête et mon regard affirmatif: « Ces ruines me font mal au cœur chaque fois que je les vois. Je les vois presque tous les jours quand je viens ici, mais chaque fois c'est pareil. Je me dis: "Quel gâchis cette division. Tout ce temps perdu." »

Par son regard tout à coup plus sérieux, Aksel semblait acquiescer au propos de son ami. Lorsque je lui demandais ce que ces ruines signifiaient pour lui, il me répondit à son tour : «Après tant d'années, je me suis habitué à leur présence. Je ne les vois plus vraiment. Elles font partie du paysage. Le jour où on les détruira, je crois que c'est une partie de moi-même, et de mon passé qui disparaîtra. » Comme me le confessèrent ensuite mes interlocuteurs, les Chypriotes turcs ne parlent pas entre eux de la ville abandonnée qui génère honte et tristesse, même lorsqu' ils se réunissent parfois dans des endroits comme la piscine ou la terrasse de l'hôtel Palm Beach où la vue de ces ruines est pourtant incontournable. Varosha appartient à l'ordre des émotions personnelles, du refoulé et de l'inconscient. Il ne faut pas en parler. La vie continue malgré la mémoire douloureuse du conflit. Des mariages sont ainsi quelquefois célébrés sur la terrasse de l'hôtel. Il est d'ailleurs intéressant de noter que le nom donné par les Chypriotes turcs à la cité en ruines (Maraş) s'inspire de l'expression locale d'un état de dépression et de mélancolie (maraz). Sur la plage, le regard inquisiteur des voyageurs voyeurs s'oppose au regard fuyant des Chypriotes turcs locaux. La plupart évitent d'ailleurs de se rendre sur cette plage du centre-ville et choisissent plutôt les plages de Glapsides, de la «Baie dorée », ou de la station balnéaire de Yeni Boğaziçi (Salamis), à quelques kilomètres plus au nord, dont le littoral a été doté de nombreux hôtels modernes depuis le boom immobilier des années 2000.

Le même sentiment de gâchis et de malaise est aussi partagé par les Chypriotes grecs, et plus particulièrement par les réfugiés. De l'autre côté de la Ligne verte, en République de Chypre, depuis la terrasse de sa maison-musée de Deryneia, pleine 


\section{CAHIERS BALKANIQUES}

146

Politique et sociétés à Chypre aujourd'hui

de nostalgie et ouverte aux visiteurs, Antonis Nicolaos observe chaque matin avec ses jumelles le grand immeuble blanc au pied duquel se situait son restaurant qu'il a quitté en août 1974, après avoir passé toute sa vie à Varosha:

Je n'imagine pas ma vie loin d'ici. J'ai fui à Larnaca avec mon fils Nicos et ma femme. Puis je suis revenu dès que possible en 1979, au plus près de la ville, au cas où nous pourrions y retourner. Varosha me manque tous les jours, même quarante ans après. J'y ai vécu les plus belles années de ma vie, j'ai rencontré ma femme là-bas et nous avons eu notre fils qui avait dix ans lorsque nous avons dû fuir. C'était un endroit magnifique.

Sur la gauche, dès l'entrée de sa maison, une pièce entière, couverte de photos et d'archives de journaux, est dédiée au souvenir. En présentant les clichés, Antonis s'indigna: «Quand je vois la ville abandonnée, je suis en colère contre l'armée turque. Elle était moderne et en avance sur le reste de l'île et maintenant, c'est un amas de ruines. » Ayant presque fait le deuil forcé d'un retour éventuel, il pense que les Chypriotes des deux communautés sont otages de la situation :

Je vis ici depuis 40 ans, mais je ne me sens pas chez moi. J'ai créé ce petit musée pour que les visiteurs sachent, et que Varosha ne tombe pas dans l'oubli. Pour que peut-être un jour mes enfants ou mes petits-enfants puissent retourner là-bas. Varosha devrait redevenir une ville bicommunautaire comme avant. Le problème, c'est l'armée turque qui ne veut pas rendre ce territoire.

\section{La contestation de la militarisation}

Plus que par des attitudes politiques et publiques de contestation de l'«occupation» (isgal) imposée par l'armée turque, comme celles prônées par la gauche alternative, très minoritaire, et par certains journalistes d'opposition, des prises de position soumises à une répression policière et à un ostracisme institutionnel importants, de nombreux Chypriotes turcs contestent indirectement la militarisation de leur territoire par des comportements d'évitement des espaces militarisés et des militaires. Au-delà des sentiments d'insécurité et de malaise, du manque de confiance envers les Chypriotes grecs et de l'accent mis sur la nécessité d'obtenir des garanties politiques, certains Chypriotes turcs critiquent plus ouvertement le rôle de l'armée turque, notamment parmi les partisans de la réconciliation. Pour Mert, un vendeur de journaux de l'avenue Kemal Gürsel à Lefkoşa, le maintien des troupes turques résulterait de considérations politiques plus que d'une réelle menace: «Je n’aime 
pas trop la présence des militaires, mais je n'ai jamais eu de problèmes. Ils tournent en rond ici et n'ont rien à faire. Tout ça, c'est de la faute des politiciens. » Ceci montrerait selon lui la situation très malaisée des Chypriotes turcs, coincés entre la volonté d'influence de la Turquie à Chypre et l'indifférence de l'Union européenne :

Le gouvernement turc veut que l'armée reste pour nous tenir sous son contrôle. Il y a beaucoup de Chypriotes turcs qui n'aiment pas ça du tout. Mais on ne peut pas faire grand-chose. On a essayé de se rapprocher de l'Europe, de voter pour le référendum [de 2004], mais ça n’a rien changé. Les Européens sont hypocrites. Ils ne veulent pas de nous. Donc nous sommes obligés de garder de bonnes relations avec la Turquie, même si nous n'aimons pas trop sa politique. Nous sommes coincés.

Le propos d'Özan, un sapeur-pompier, retranscrit de même bien la position inconfortable des Chypriotes turcs, tiraillés entre besoin de sécurité et volonté d'autonomie, deux principes aux implications contradictoires :

Le vrai problème, c'est l'armée turque. Les Chypriotes grecs considèrent qu'elle n'a rien à faire ici. Moi aussi je pense qu'elle devrait partir. Mais puisque les Chypriotes grecs ne veulent pas réellement négocier avec nous, nous avons besoin de la Turquie pour défendre nos intérêts, car personne ne veut nous entendre. Mais pour la Turquie, Chypre n’est pas sa priorité. Elle se contente de maintenir sa présence militaire ici.

Certains Chypriotes turcs tels que Murat, un serveur, sont beaucoup plus critiques, accusant les militaires turcs de «se croire tout permis » et de « vouloir occuper Chypre du Nord pour faire du business ». Pour lui, « dire qu'ils nous protègent est un prétexte pour rester. Les Chypriotes sont pacifiques. Tout le monde sait qu'une nouvelle guerre est impossible. » Le propos de Serçi, un militant du YKP, traduit le même type d'exaspération liée à une présence militaire massive et aux multiples interdits qui pèsent sur la vie quotidienne:

Les militaires turcs, il y en a plein partout! Il faut voir le samedi durant leur permission. Dans la vieille ville, on ne voit qu'eux! Comme ils se baladent toujours à plusieurs, c'est facile de les repérer. Tant qu'ils seront là, ça voudra dire que la situation n'est pas bonne. Il faut qu'ils nous laissent vivre tranquilles et qu'ils rentrent chez eux en Turquie. 
Örsan, un retraité, rend les militaires « responsables de la situation», car « depuis plus de 35 ans qu'ils sont là, rien n'a changé. Je n'ai rien contre la Turquie, mais je trouve que l'armée turque devrait rentrer chez elle. Ce serait mieux pour tout le monde. » Pour lui, la peur d'une nouvelle marginalisation des Chypriotes turcs dans le cas d'un retrait de l'armée serait un fantasme commode utilisé politiquement afin de maintenir le statu quo:

Les Chypriotes grecs ne feront rien en cas de retrait de l'armée turque. Ils savent très bien que les gens d'ici n'accepteront pas une occupation du Nord. C'est comme avec l'ouverture de la frontière. Certains disaient que ce serait l'invasion! Mais il ne s'est rien passé du tout. Les Chypriotes veulent la paix.

\section{Conclusion : la souveraineté comme champ de pratiques sociales}

Au final, l'étude de l'affirmation de la souveraineté turque à Chypre du Nord à travers la militarisation montre que l'appropriation et la (re)définition des propriétés matérielles d'un espace physique sont le produit d'un processus politique sur un territoire donné. Loin d'émerger par décret lors de réunions diplomatiques, la « réalité » de la souveraineté sur le terrain et l'appropriation d'un territoire par une communauté politique se fonde plutôt sur un processus de contrôle et de redéfinition de l'espace grâce à la défense militaire et à la définition de frontières réelles et symboliques. Les frontières ne sont en effet pas des « faits spatiaux avec des conséquences sociologiques, mais davantage des faits sociologiques qui prennent des formes spatiales, car elles sont avant tout des constructions sociales et des technologies politiques ${ }^{22}$. $\gg$ À Chypre du Nord, à travers le maintien du confinement et l'institutionnalisation de la « RTCN », une entité politique symboliquement distincte de la République de Chypre, il s'agit de même de changer, en s'appuyant sur la variable temporelle, les perceptions que se font les acteurs sociaux de leur propre espace physique, rendant ainsi d'autant plus difficile le retour au statu quo ante bellum. La souveraineté de la « RTCN » n'existe donc pas simplement parce qu'il s'agirait de la « volonté du souverain », de l'armée turque qui contrôle ce territoire, mais parce que les autorités chypriotes turques elles-mêmes ont enclenché un processus politique visant à s'approprier le territoire de Chypre du Nord à travers un ensemble de procédures bureaucratiques et instrumentales formalisées qui « font exister » au quotidien pour les Chypriotes turcs un État dont l'existence demeure pourtant contestée.

22. Bigo et al., 2009 , p. 7. 
La souveraineté se construit ainsi au quotidien et sur le long terme sur un territoire donné, à travers des processus de négociation et de contestation entre les acteurs sociaux dont le résultat des luttes donne un sens à leur espace physique et social. Dans le contexte spécifique de l'État de facto de Chypre du Nord, la militarisation de l'espace social induite par la présence durable de l'armée turque affecte le ressenti des Chypriotes turcs et l'image qu'ils se font de leur propre territoire. Ils sont ainsi partagés entre des sentiments de menace et de reconnaissance à l'égard de l'armée turque, qui coexistent avec le malaise et l'impression d'être étouffés dans un territoire isolé et marginalisé par la communauté internationale. Même s'ils sont pleinement conscients des limites de la «souveraineté » de leur entité autoproclamée, ils contribuent quotidiennement par leurs pratiques sociales à «vivre avec»les contraintes de la militarisation, et à « faire exister » leur «État » qui administre leur territoire, leur donne accès à l'éducation et leur fournit les services sociaux nécessaires, même s'il demeure très dépendant de la Turquie, tant financièrement, militairement que politiquement. La souveraineté ne se fonde donc pas seulement sur un processus culturel et symbolique de reconstruction d'un imaginaire national, mais elle émerge aussi à travers un processus politique d'appropriation militaire, architecturale et géographique de l'espace.

\section{Bibliographie}

\section{Monographies}

Aвu El-Haj Nadia, 2002, Facts on the Ground. Archeological Practice and Territorial Self-Fashioning in Israeli Society, University of Chicago Press, Chicago, $363 \mathrm{p}$.

Agamben Giorgio, 2002, Moyens sans fins. Notes sur la politique, Rivages Poche, Paris, 153 p.

AxçAli Emel, 2009, Chypre: un enjeu géopolitique actuel, L'Harmattan, Paris, $360 \mathrm{p}$.

Benvenisti Meron, 2002, Sacred Landscape. The Buried History of the Holy Land since 1948, University of California Press, California, 394 p.

Copeaux Étienne \& Mauss-Copeaux Claire, 2005, Taksim! Chypre divisée (1964-2005), Éditions Aedelsa, Lyon, 235 p. 
150 Politique et sociétés à Chypre aujourd'hui

Debos Marielle, 2013, Le Métier des armes au Tchad. Le gouvernement de l'entre-guerres, Khartala, Paris, 264 p.

Drevet Jean-François, 2000, Chypre en Europe, L'Harmattan, Paris, 328 p.

Dubors Vincent, 1999, La Vie au guichet. Relation administrative et traitement de la misère, Economica, Paris, 224 p.

Grafmeyer Yves \& Joseph Isaac, 1979, L'École de Chicago: naissance de l'écologie urbaine, Armand Colin, Paris, 377 p.

Hetherington Kevin, 1998, Expressions of Identity: Space, Performance, Politics, Sage, London, 192 p.

Нıвоu Béatrice, 2006, La Force de l’obéissance. Économie politique de la répression en Tunisie, La Découverte, Paris, 372 p.

Hirst Paul, 2005, Space and Power. Politics, War and Architecture, Polity Press, Cambridge, $272 \mathrm{p}$.

Новsваwм Eric \& Ranger Terence (eds.), 1983, The Invention of Tradition, Cambridge University Press, Cambridge, 381 p.

Messiant Christine, 2008, L'Angola postcolonial, tome 2: Sociologie politique d'une oléocratie, Khartala, Paris, 432 p.

Navaro-Yashin Yael, 2012, The Make-Believe Space. Affective geography in a Postwar Polity, Duke University Press, Durham, 296 p.

PegG Scott, 1998, International Society and the de facto State, Aldershot, Ashgate. $322 \mathrm{p}$.

Schmitт Carl, 1988 [1922], Théologie politique I, Gallimard, Paris, 204 p.

Weisman Alan, 2007, Homo Disparitus, Flammarion, Paris, 352 p. 


\section{Articles et participations à des ouvrages}

Bigo Didier, Bocco Ricardo \& Piermay Jean-Luc, 2009, «Logiques de marquage : murs et disputes frontalières $\gg$, Cultures et Conflits, $\mathrm{n}^{\circ} 73$, p. 5-20.

Chanu Pauline \& Gleizes Philippe, 2014, «Varosha, la cité fantôme qui hante les Chypriotes turcs», URL: https://ipressdestress.wordpress. com/2013/05/30/varosha-la-cite-fantome-qui-hante-les-chypriotes-turcs/ (consulté le 28/11/2019).

Clochard Olivier, 2008, «Jeux de frontières à Chypre: quels impacts sur les flux migratoires en Méditerranée orientale ?», Géoconfluences. URL: http:// geoconfluences.ens-lyon.fr/doc/typespace/frontier/FrontScient8.htm

Hirsch Éric, 1995, "Landscape: Between place and space" in Hirsch Éric \& O’Hanlon Michael (eds.), The Anthropology of Landscape: Perspectives on Place and Space, Clarendon Press, Oxford, pp. 1-30.

Jackson Robert \& Rosberg Charles, 1982, “Why Africa’s Weak States Persist: The Empirical and the Juridical in Statehood”, World Politics, vol. 35, $\mathrm{n}^{\circ} 1$, pp. 1-24.

Navaro-Yashin Yael, 2010, “The materiality of sovereignty: Geographical expertise and changing place names in Northern Cyprus" in Diamandouros Nikiforos, Dragonas Thalia \& Keyder Çağlar (eds.), Spatial Conceptions of the Nation: Modernizing Geographies in Greece and Turkey, I. B. Tauris, London, pp. 115-130.

Papadakis Yiannis, 2003, "Nation, narrative and commemoration: Political ritual in divided Cyprus", History and Anthropology, vol. 14, n 3, pp. 253-270.

\section{Liste des entretiens}

À Lefkoşa.

Ali, 32 ans, agent d'accueil, hôtel City Royal, rue Kemal Asik, 3/2/2012.

Ismail, gérant de la pension Seslikaya, rue Asmaalti, 4/2/2012.

Mert, 27 ans, vendeur de journaux, avenue Kemal Gürsel, 5/2/2012. 
152 Politique et sociétés à Chypre aujourd'hui

Huseyin, militaire, place Ismet Inonü, 5/2/2012.

Özan, 31 ans, policier, rue Abdullah Parla, 5/2/2012.

Murat, 29 ans, serveur, European café, rue Baf Caddesi, 5/2/2012.

Metin Çatan, 64 ans, membre du bureau du parti démocrate (DP), rue Server Somuncuoğlü, 6/2/2012.

Cüneyt Küçük, 33 ans, membre du bureau du parti de l'Unité nationale (UBP), rue Sarayönü, 6/2/2012.

Ege, 59 ans, policier, avenue Bedrettin Demirel, 7/2/2012.

Mustafa, 37 ans, commerçant, avenue Bedrettin Demirel, 7/2/2012.

Tansel Doratli, 55 ans, vice-président du parti de la Démocratie et de la confiance (DGP), avenue Osman Paşa, 8/2/2012.

Tahsin Ertuğruloğlü, 53 ans, président du parti de la Démocratie et de la confiance (DGP), avenue Osman Paşa, 8/2/2012.

Örsan, 62 ans, retraité, porte de Kyrenia, 8/2/2012.

Kemal, 31 ans, militaire turc, place de Kyrenia, 10/2/2012.

Murat Kanatli, 44 ans, secrétaire général du parti de la Nouvelle Chypre (YKP), rue Tanzimat, 14/2/2012.

Serçi, 57 ans, militant du YKP, rue Tanzimat, 14/2/2012.

Nihat, 48 ans, professeur d'histoire, lycée chypriote turc, avenue Cemal Gürsel, $17 / 2 / 2012$.

Özkan Yorgancioğlü, secrétaire général du parti républicain turc (CTP), avenue Bedrettin Demirel, 22/2/2012.

Leman Aslim, 46 ans, conseillère du gouvernement (KKTC Başbakanlik), 23/2/2012. 
À Gazimağusa et autres lieux.

Aksel et Koray, enseignants à la retraite, 25/3/2014.

Antonis Nicolaos, retraité, Deryneia, 26/3/2014.

Özer, serveur chypriote turc, Girne, 9/4/2014.

Mertkan Hamit, 12/4/2014.

Akif, serveur, restaurant Blue Lagoon, rue Nadir, 13/4/2014.

Résumé: en se fondant sur des enquêtes de terrain menées en 2012 et en 2014 à Nicosie-Nord (Lefkoşa/Lefkosia) et Famagouste (Gazimağusa/Ammochostos), cet article propose une ethnographie de la militarisation de l'espace à Chypre du Nord et de son impact psychosocial. Il suggère une redéfinition anthropologique de la souveraineté à partir de sa dimension spatiale. Il montre que le contrôle territorial imposé par l'armée turque depuis 1974, même s'il demeure «illégal » en droit international et reste considéré comme une «occupation» (isgal) par les militants de la paix, n'en demeure pas moins très réel et durable sur le terrain. L'ethnographie des ruines de guerre de Varosha (Maraş) montre que la militarisation modifie les propriétés matérielles de l'espace, mais aussi les représentations que se font les Chypriotes turcs de leur propre territoire et du conflit. Elle empêche donc le retour au statu quo ante bellum et joue aussi une fonction performative visant à « faire exister » la « République turque de Chypre du Nord $\gg$.

Mots-clefs: militarisation, anthropologie politique, souveraineté, conflit, Chypre du Nord, République de Chypre, Varosha, 1974: intervention turque à Chypre et occupation, 1983 : proclamation unilatérale de la République turque de Chypre du Nord, 2004 : plan Annan, 1983, géopolitique

Abstract: On the basis offeldworks conducted in 2012 and 2014 in North-Nicosia (Lefkoşa/Lefkosia) and Famagusta (Gazimağusa/Ammochostos), this paper proposes an ethnographical study of the militarization of space and of its psychosocial impact in Northern Cyprus. It suggests an anthropological redefinition of sovereignty based on its spatial dimension. It shows that the territorial control imposed by the Turkish army since 1974, though "illegal" in international law and considered as an "occupation" (isgal) by peace militants, is nevertheless important and durable in practice. The 
ethnography of war ruins in Varosha (Marass) shows that the militarization modifies space's material properties but also Turkish Cypriots' representations of their own territory and of the Cyprus conflict. Thus, militarization impedes the return to the status quo ante bellum, while playing a performative role by helping to create the "Turkish Republic of Northern Cyprus".

Keywords: militarization, political anthropology, sovereignty, conflict, Northern Cyprus, Republic of Cyprus, Varosha, 1974: Turkish intervention in Cyprus and occupation, 1983: unilateral oroclamation of the Turkish Republic of Northern Cyprus, 2004: Annan plan, 1983, geopolitics

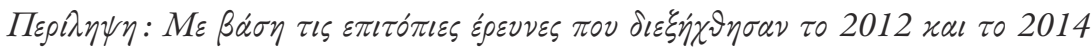

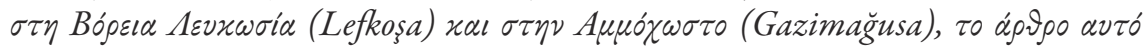

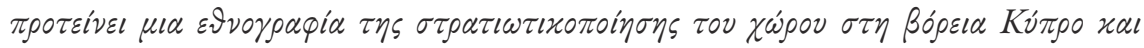

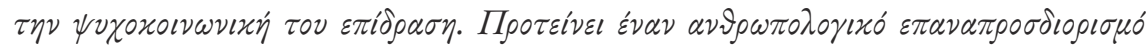

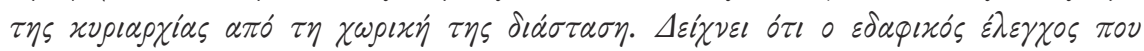

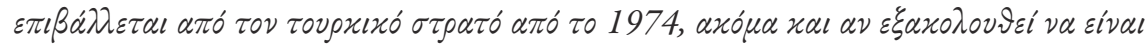

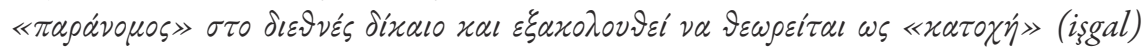

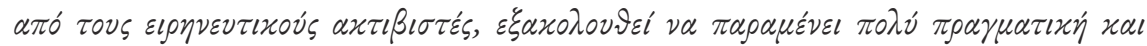

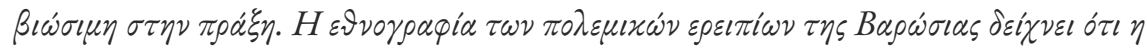

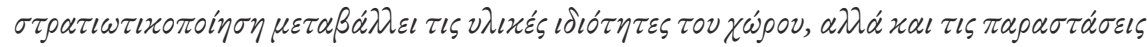

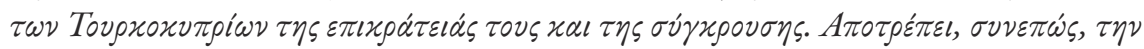

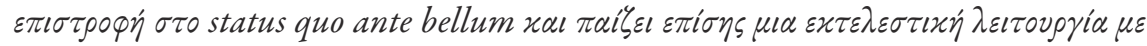

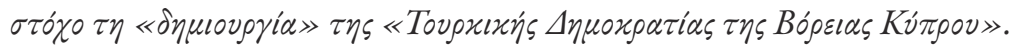

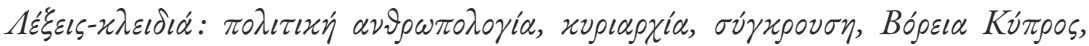

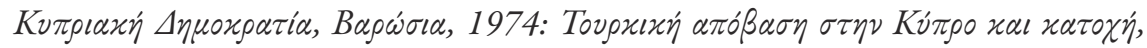

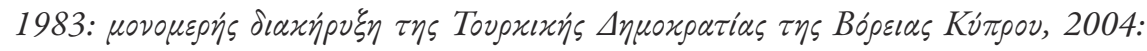

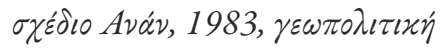

Anabtar kelimeler: militarizasyon, siyasi antropoloji, egemenlik, çatışma, Kuzey

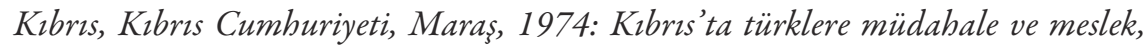
1983: Kuzey Kibris Türk Cumburiyeti'nin tek tarafl ilanı, 2004: Annan planı, 1983, jeopolitik

Клучни зборови: милитаризачија, политичка антропологија, суверенитет, конфликт, Северен Кипар, Република Кипар, 1974: турска интервенщија во Kипар и окупащија, 1983: еднострано прогласувате на Турската Република Северен Кипар, 2004: план Анан, 1983 година, геополитика 